\title{
Improving the Health Workforce Distribution in Remote and Rural Areas of Ethiopia: An Evidence-Based Policy Brief
}

\author{
Serebe Abay*, Amanuel Dibaba, Yosef Gebreyohannes, Desalegn Ararso, Fasil Mengistu, \\ Mamuye Hadis
}

Technology Transfer and Research Translation Directorate, Ethiopian Public Health Institute, Addis Ababa, Ethiopia

\author{
Email address: \\ serebeabay@yahoo.com(S. Abay) \\ ${ }^{*}$ Corresponding author
}

\section{To cite this article:}

Serebe Abay, Amanuel Dibaba, Yosef Gebreyohannes, Desalegn Ararso, Fasil Mengistu, Mamuye Hadis. Improving the Health Workforce Distribution in Remote and Rural Areas of Ethiopia: An Evidence-Based Policy Brief. Journal of Investment and Management. Vol. 7, No. 2, 2018, pp. 45-52. doi: 10.11648/j.jim.20180702.11

Received: January 17, 2018; Accepted: February 11, 2018; Published: April 17, 2018

\begin{abstract}
Human Resources for Health (HRH) constitute the most vital component of health systems. However, the HRH picture of Ethiopia has remained critically low and characterized by geographic mal-distribution. This brief aimed to show the major causes for poor health workforce distribution and to suggest possible policy options. We reviewed relevant evidence describing the problem and feasible options to address the problem, the barriers to implement those options, and implementation strategies to address these barriers. We searched electronic databases of systematic reviews and supplemented with local evidences. In our review, we found different options that help to improve health workforce distribution in the remote and rural areas of the country. Systematic reviews on impact of task shifting, clinical rotations in rural areas during studies and financial incentives have shown favourable results that may lead to increase the number of health workforce working in rural and underserved areas. But none of the studies assessed the costs and cost effectiveness of the suggested options. Therefore, given the limitations of the currently available evidence, there is a need for rigorous evaluative research on the cost effectiveness of each option prior to widespread implementation.
\end{abstract}

Keywords: Policy Brief, Health Workforce Distribution, Health System, Ethiopia

\section{Background}

Human Resources for Health (HRH) constitute the most vital component of health systems. It is one of the six building blocks of the WHO framework for health systems [1]. Effective and equitable health service provision depends to a large degree on the availability, competence, motivation and distribution of human resources for health. However, worldwide the geographical distribution of health workers is skewed towards urban and wealthier areas [2]. For example, $37 \%$ of the world's health workforces work in the WHO region of the Americas, which accounts for only $10 \%$ of the global burden of disease. Whereas, with $24 \%$ of the global burden of disease the WHO African Region, is served by only $3 \%$ of the world's health workforces [3].

In Africa, the health workforce has been very low and is unable to match the rapidly growing population [4].
Particularly, Sub-Saharan Africa (SSA) has the lowest ratios of health workers to population in the world [5]. This shortage of health workforce and poor distribution continue to be problem of health systems and hinder attainments of health-related goals including Universal Health Coverage (UHC) in low and middle-income countries (LMICs) [6].

According to the 2006 World Health Report, globally 57 countries are in a serious health workforce crisis out of which 36, Ethiopia included, are in the African region [3]. The $\mathrm{HRH}$ picture of Ethiopia has remained critically low and has been characterized by geographic mal-distribution, skills imbalance, staff shortages, low retention and low productivity [7]. As a result, the numbers of health professionals in various parts of the country remains lower than the standard [8]. Like other LMICs, Ethiopia suffers from an acute shortage of health workers at every level, and the rural areas, in which majority $(85 \%)$ of the population have been chronically under-served [9]. Considering 
population numbers, in Ethiopia the ratio of health workers to population showed a heavy urban bias particularly of higher level health professionals. Especially the problem was worst in agrarian and pastoralist regions [8, 10]. For instance, the physician to population ratio in Gambella, Oromia and SNNPR regional states was computed to be 1: 27,357, 1: 56,645, and 1: 57,059, respectively. These figures are not only far below the international standard $(1: 10,000)$ but also very low compared to the 1: 6,062 ratios for Addis Ababa $[11,12]$. In Afar, Somali and Benishangul Gumz regional states, which were under served regions, the health workers density (doctors, nurses and midwives) ratio was 0.5 for 1000 population [11]. This was four-fold less than the standard set by WHO for developing countries to achieve minimum level of key health interventions showing that extreme gap which needs to be bridged. A national facility-based study on pharmacist workforce in Ethiopia also showed that pharmacists were found unevenly distributed between regions. For instance, in Afar alone, a remote and underserved region, the density of pharmacist per 100,000 population was 0.66 as compared to Addis Ababa which was 29.88 [13].

Even though about $96 \%$ of Ethiopian population was living outside the capital, $90 \%$ of the public hospitals were concentrated in the regional cities [14]. Approximately half $(45.9 \%)$ of the pharmacists were working in Addis Ababa. These indicate that majority of the health institutions in the country were running their activities without pharmacists [13]. The available stock of health workforce of the country was also not fairly distributed among regions. For instance, out of the 2923 physicians (general practitioners and specialists) classified as working in the public sector in $2012 / 13$ fiscal year, about $20 \%$ of them were working in the capital, Addis Ababa [11], home to only less than $4 \%$ of the population [15]. The trend was the same outside the capital, physicians work in major cities of the regions [16].

This imbalanced distribution of health personnel can contribute to great disparities in health outcomes between the rural and urban population. One instance in this regard is skilled providers attended births. According to the 2011 Ethiopian Demographic and Health Survey (EDHS), only 4\% of rural births were attended by skilled personnel while skilled providers attended $51 \%$ of births in urban $[17,18]$, a situation indicating a considerable difference in the services accessible to rural and urban women.

Another parameter that shows service coverage difference between urban and rural is births by caesarean section. According to the 2011 DHS report, in seven out of the 11 regions the rate of caesarean section was below 2\%. Rates were in the range of $8-10 \%$ in Gambella, Harai and Dire Dawa. The highest rate of caesarean section delivery was reported in Addis Ababa at 20\%, even though 93\% of births occurred in rural areas $[19,20]$. There are also significant variations between rural and urban settings with regards to under-five child mortality, $83 / 1000$ and $114 / 100$ respectively [21].

To tackle this challenge the country underwent rapid expansion of health worker production and staffing along with the expansion of health facilities in the past years. However, despite this rapid increase in production, recruitment and deployment of health workers, geographical imbalances of the available health workforce is still a challenge to achieve health service coverage as fewer health workers are deployed in underserved communities with higher health needs [7]. The objective of this evidence brief is, therefore, to show the size and major causes of the poor health workforce distribution in remote and rural areas of Ethiopia and to suggest possible policy options that can improve the health workforce availability in rural parts of the country.

\section{Methods}

We searched global research evidence from systematic reviews and local evidence to find the causes for poor health workforce distribution and the available options to solve the problem. We searched particularly for relevant systematic reviews on the effectiveness of the policy options and implementation strategies. We supplemented with information extracted from other relevant studies and locally available documents.

The methods used to prepare this policy brief are described in detail elsewhere $[22,23]$. The problem that the policy brief addresses was clarified iteratively through discussion among the authors, review of relevant documents and research. Research describing the size and causes of the problem was identified by reviewing government documents, routinely collected data, searching PubMed and Google Scholar, through contact with key informants, and by reviewing the reference lists of relevant documents that were retrieved.

Strategies used to identify potential policy options to address the problem included considering interventions described in systematic reviews and other relevant documents, considering ways in which other jurisdictions have addressed the problem, consulting key informants and brainstorming.

We searched electronic databases of systematic reviews, including: the Cochrane Library (CENTRAL, Cochrane Database of Systematic Reviews), Support Summaries, PDQ Evidence, Health Systems Evidence and supplemented these searches by checking the reference lists of relevant policy documents and with focused searches using PubMed, Google Scholar, and personal contacts to identify systematic reviews for specific topics. The final selection of reviews for inclusion was based on a consensus of the authors.

Potential barriers to implement the policy options were identified by brainstorming using a detailed checklist of potential barriers (SURE guide for identifying and addressing barriers) to implement the suggested policy options. Implementation strategies that address identified barriers were identified by brainstorming and reviewing relevant documents [22].

A policy dialogue (structured discussion) focused on this evidence-based policy brief was conducted with relevant 
expertise and perspectives including policy makers, civil societies, the mass media, researchers and other stakeholders. The aim of the dialogue was to enrich the policy brief and to have well-informed health policy decisions but not to reach a consensus or decide.

\section{Result and Discussion}

\subsection{Factors Underlying the Problem}

In our review, we found many push and pull factors for the poor distribution of the health workforce in remote and rural parts [2]. Push factors were those factors that occur within the sector, forcing professionals to leave. These included; low salary, poor incentives, poor working condition, inadequate resources to work effectively, high work load, poor human resource management and limited /no training and educational opportunities [24, 25].

On the other hand, pull factors were the deliberate and/or unintended actions that attract health professionals out of the government services. These includes; higher payment, higher incentives, better working condition, better resource for work, good career structure and good education and training opportunities [24, 26].

Although little research has been done to determine what factors motivate in driving health workforce from rural settings, in Ethiopia the causes of poor health work force distribution in remote and rural areas include unattractive local environment, poor motivation and retention schemes, work-related factors, individual factors and organizational environment.

\subsubsection{Poor Motivation and Retention Schemes}

Studies in the country have shown that insufficient motivation and retention mechanisms were causes for the poor distribution of the health workforce in remote and rural areas $[25,27]$.

\subsubsection{Individual Factors}

Individual factors such as a person's social background, age, gender, education, values, beliefs, etc have been found to influence individual's decision whether to work in rural areas or not. For example, growing up in a rural community has been associated with higher probability to practice in rural areas [2].

\subsubsection{Organizational Environment}

According to Serneels P. etal, doctors working in urban public facility received more training, frequent formal evaluations, daily checks of presence, and monitoring from clients through complaint offices than their rural public counterparts [9]. In Ethiopia, inadequate and incomplete communication and feedback between Federal Ministry of Health (FMoH) and Regional Health Bureaus (RHBs) was found to be one problem related to organizational environment. The same holds true for communications from the RHBs to Woreda [Administrative structure equivalent to district] and down to health facility level. Within health facilities, there is a limited human resources management capacity for performance planning, regular supportive supervision and constructive feedback to improve health workers performance [7, 25].

\subsubsection{Local Environment}

Like most LMICs, in Ethiopia the importance of general living conditions, including staff accommodation, schools and qualified teachers in remote rural areas frustrates health professionals and forces them to find jobs in urban areas with better infrastructure [26].

\subsubsection{Work-Related Factor}

Working conditions, including organizational arrangements, management support and availability of equipment, have been identified factors in deciding whether to leave or stay in remote areas [2,5]. A survey on employee satisfaction conducted at FMoH and selected RHBs, as well as staff exit interview analysis identified that lack of adequate infrastructure, space and facilities, poor management environment, high workload and insufficient budget, equipment and supplies were underlying causes for employee dissatisfaction and high attrition rates [4, 7]. Increased and uneven workload was one of the factors that demoralize health professionals. A study conducted on health workers motivation in Ethiopia showed that $55.1 \%$ of physicians and $48.2 \%$ of nurses are unable to find sufficient time to complete their daily tasks $[7,18,26]$.

\subsection{Suggested Policy Options}

The FMoH has recently set an ambitious Health Sector Transformation Plan (HSTP) to improve equity, coverage and utilization of essential health services and improve quality of health care in all corners of the country [28]. Indeed, the realization of this stretched plan largely depends on the availability of the right number and skill mix of professionals as the health workforce is the key to effective health services. Despite this fact, Ethiopia has currently major $\mathrm{HRH}$ challenges including shortage, and urban/rural and regional disparities.

Therefore, in improving the health workforce distribution in rural parts of the country and there by contribute to the implementation of the transformation plan, the following options were considered: (i) Task Shifting (ii) Educational Strategies (iii) Strengthening Financial and Non-Financial Incentives and (iV) Continuous Professional Development.

Given the nature and variety of factors influencing the decision to work in rural and remote areas, a single intervention is unlikely to be successful. As a result, the options suggested need to be implemented in a way that they complement one another.

\subsubsection{Task Shifting for Increasing Number of Health Workforce}

Task shifting is the rational re-distribution of tasks among health workforce teams in which specific tasks are moved, where appropriate, from highly qualified health workers to health workers who have fewer qualifications in order to 
make more efficient use of the available HRH [29]. By reorganizing the workforce in this way, task shifting can ensure more efficient use of the human resources available in underserved areas. For example, when doctors are in short supply, a qualified nurse could replace the role of doctors and so on $[30,31]$.

Task shifting has the potential for improving the retention of health workers in remote areas where the needs for health care services are higher than the available health personnel [32].

Impacts of Task shifting: Different Systematic reviews have assessed evidence regarding the impact of task shifting. They found that;

i. Substitution of doctors with nurse practitioners may result in little or no difference in quality of care or patient outcomes [33].

ii. Substitution of doctor with nurse in primary care may lead to similar health outcomes for patients [34].

iii. Using lay health workers (LHWs), compared to usual healthcare service may increase care seeking behavior for children under five and reduce morbidity in children under five [35].

\subsubsection{Educational Strategies}

The way health care professionals are trained, the skills they acquire and the situations they are exposed to during their training are important determinants of their future practice choices, including location [2]. Considering this, many countries' medical schools are reforming their curriculum with a view to producing graduates better prepared and more willing to work in underserved areas. Hence, in strengthening the medical education system with the objective of producing graduates who are willing to work in rural areas, the following interventions are suggested;

Strategy 1: Targeted recruitment of students into medical school

Practice from different countries has shown that increasing overall enrolment of new trainees in medical schools alone has no impact on rural employment [36]. Newly graduated professionals can either migrate or opt to practice in the urban private sector or even work in other sectors. This shows the need for special selection of students into medical schools, i.e. targeted recruitment policies which may possibly increase retention of health professionals assigned to rural areas. Recruiting students from rural areas seems to be effective as health workers with a rural background are more likely to practice in rural areas after completing their studies [2].

Impacts of targeted recruitment of students into medical schools: A systematic review on interventions for increasing the proportion of health professionals practicing in rural and other underserved area failed to identify any study meeting the inclusion criteria [37]. However, primary studies in the review have found that recruiting medical students with rural background may increase number of medical doctors working in rural and underserved areas. The effects on retention of health professionals in rural areas are uncertain.

Strategy 2: Clinical rotations in rural areas during studies
Clinical rotation in rural areas aims at exposing students to rural community experiences in order to increase interest in rural careers after their graduation [38]. Such practice may allow health workers to gain awareness of rural health. This is because medical education/ training, particularly for physicians, is typically conducted in tertiary care institutions using the latest available technology and diagnostic tools. Once medical studies finish, students are left without skills to deal with health situations in areas where advanced technology and tools are not available [36]. Therefore, clinical placements in rural areas during studies is one way to expose students to the health issues and conditions of service within rural communities and give them a better understanding of the realities of rural health work.

Impact of clinical rotations in rural areas during studies: A systematic review evaluated the impact of medical students' rural exposure to improve the distribution of health professionals in rural areas [38]. The SUPPORT summary based on this systematic review found that exposure to clinical rotations in rural settings may influence the subsequent intention of medical students to work in underserved areas [39].

\subsubsection{Strengthening Financial and Non-Financial Incentives}

The WHO defines incentives as all the rewards and punishments that providers face because of the organizations in which they work, the institutions under which they operate and the specific interventions they provide [40]. More tightly defined, an incentive is an explicit or implicit financial or non-financial reward for performing an activity. Incentives can also be viewed as the factors and/or conditions within health professionals' work environments that enable, encourage and motivate them to stay in their jobs and in their profession [41].

Strategy 1: Financial incentives for health workers in remote and rural areas

Financial incentive programs are one of the few health policy interventions intended to improve the distribution of human resources for health [42]. Financial incentives encompass all additional payments aimed at boosting the morale of the health workers. This include: Car allowance, housing or housing allowance, access to loans at lower negotiated market rates from financing institutions to purchase houses or cars.

Impact of financial incentives: A systematic review evaluated the impact of financial incentives for return to service in under-served area [38]. A SUPPORT summary, based on this systematic review, found that financial incentive programmes may lead to increases in the number of health workers practising in under-served areas [39].

Strategy 2: Non-financial incentives for health workers in remote and rural areas

Non-financial incentives are important determinants for the length of stay of health workers in rural and remote areas [2]. Non-financial incentives include: the provision of rewards, schools for children, promotion, housing, free 
transportation, health insurance and life insurance policy and so on. To be effective, these benefits have to be larger than the opportunity costs associated with working in rural areas such as the possible additional income generated from working in the urban private sector [2].

Impact of non-financial incentives: We couldn't find a systematic review on the impact of non-financial incentives in retaining health workers in rural areas. However, there are best practices from different countries.

For example, a common strategy in Mozambique, Kenya and Chile is to offer government housing to staffs [30, 43, 44]. In Zambia the health workers retention scheme includes lower car loan rates and scholarships to send children to better schools in other areas. This incentive package appears to have an impact on attracting doctors in Zambia to rural areas who otherwise would not have gone to the rural posts [30].

\subsubsection{Continuous Professional Development (Support)}

Continuing Professional Development (CPD) for health workers is the process by which individual healthcare professionals maintain and improve standards of healthcare practice, through development of knowledge, skills, attitudes and behaviour [45]. It may be called refresher training, continuing education, in-service training or Continuing Medical Education. Professional development strategy includes; provision of adequate equipment and supplies, supportive supervision, better career paths for rural and remote area posts and creating strategies to increase public recognition [2].

Professional and personal support interventions address shortages and mal-distribution of staff, by improving responsiveness to staffing needs and addressing their causes of dissatisfaction and stress. This is done through addressing a sense of isolation when working in remote areas through outreach support from specialists, addressing the difficulty of combining professional and personal life using refresher programmes and flexible rosters and motivating staff by providing professional development or career opportunities [46].
Impact of Continuous Professional Development: We couldn't come across a systematic review on the impact of continuous professional support on retention of health professionals in rural areas. However, questionnaire-based surveys suggest that professional and personal support might also influence health professionals' choice to work in underserved areas [47].

\subsection{Implementation Considerations}

Task shifting, educational strategies, strengthening financial and non-financial incentives, (targeted selection of students in to medical schools and clinical rotation) and continuous professional development are potential solutions suggested to improve the health work force in rural and remote parts of Ethiopia. The implementation of these potential options includes both opportunities and challenges. It is therefore important to consider possible barriers and enablers, so that benefits arising from enablers can be taken as an opportunity while properly addressing the barriers.

Enablers of improving health work force in rural parts of Ethiopia include:

a) Existence of a strong government commitment to improving health workforce to enhance the health status of Ethiopians [7].

b) Existence of previous experience on task shifting on HIV services [20, 31].

c) The launch of heath sector transformation plan, which aims to make health facilities in 'Woredas' highperforming facilities - 'Woreda' transformation [28].

d) Availability of donors and different project initiations in support of health workforce (projects like for example MEPI).

e) The preparation of a national human resource for health strategic plan [7].

Potential barriers to the implementation of the four options and strategies to address those barriers are summarised in tables 1-7.

Table 1. Barriers to the implementation of all options.

\begin{tabular}{lll}
\hline Barriers & Descriptions & Implementation strategies \\
\hline \multirow{2}{*}{$\begin{array}{l}\text { Financial } \\
\text { constraint }\end{array}$} & - Implementation of each of the options require a & - Piloting and costing of incentives, better use of existing resources through \\
& substantial investment of financial resource & coordination of governmental and non-governmental initiatives, and \\
& & - Resource mobilization \\
& - applying for additional funds from donors and reallocating public funds) \\
\hline
\end{tabular}

Table 2. Barriers to the implementation clinical rotation and continuous professional development options.

\begin{tabular}{lll}
\hline Barriers & Descriptions & Implementation strategies \\
\hline & - Lack of safe, reliable, accessible, and affordable methods of transportation (e.g., limited public & - Organizing some on-job \\
$\begin{array}{l}\text { Geographic } \\
\text { transportation options) }\end{array}$ & $\begin{array}{l}\text { - Staff working in the rural areas are unable to attend CPD activities because of poor transport links } \\
\text { and the absence of staff to fill their posts when away }\end{array}$ & - Rural infrastructure \\
& development & \\
\hline
\end{tabular}

Table 3 Barriers to the implementation of task shifting.

\begin{tabular}{lll}
\hline Barriers & Descriptions & Implementation strategies \\
\hline Resistance to & - Resistance of accepting task shifting from the & - Establishing a system that ensure adequate recognition, equitable allocation \\
change from health & health workers and service users may be a problem. & of resources, training, compensation and monitoring to ensure quality of care, \\
workers as well as & - Lack of appropriate recognition and status, even if & worker morale and staff retention. (49). \\
service users & staffs who assume new tasks are performing the & - Formal recognition of new types of health workers through credentialing \\
\hline
\end{tabular}




\begin{tabular}{lll}
\hline Barriers & Descriptions & Implementation strategies \\
\hline & tasks of higher-level workers & $\begin{array}{l}\text { (licensure, registration, certification or accreditation) can help to overcome } \\
\text { resistance to change. (32). }\end{array}$ \\
$\begin{array}{l}\text { Over burdening of } \\
\text { the existing staff }\end{array}$ & $\begin{array}{l}\text { - Patient outcomes may be compromised in settings } \\
\text { where staffs are already overworked if the current } \\
\text { tasks are not shifted to lower levels of workers. }\end{array}$ & $\begin{array}{l}\text { - A system should be arranged so that if higher level workers' tasks are } \\
\text { shifted to lower level workers, these latter groups' tasks should, in turn, shift } \\
\text { to other non-professional cadres. }\end{array}$ \\
$\begin{array}{l}\text { Inadequate } \\
\text { supportive } \\
\text { supervision }\end{array}$ & $\begin{array}{l}\text { - Adequate knowledge and skills are required for } \\
\text { supportive supervision, but health workers capable } \\
\text { of providing supportive supervision are also } \\
\text { experiencing heavy workloads and high staff } \\
\text { turnover. }\end{array}$ & $\begin{array}{l}\text { - Introducing new models for supportive supervision, such as those based on } \\
\text { mobile technology, may be used to provide support to staffs who assume new } \\
\text { task in resource-limited settings. (50). } \\
\text { - Measures to limit staff turnover and increase mentoring and supervision } \\
\text { capacity need to be planned from the outset. }\end{array}$ \\
\hline
\end{tabular}

Table 4. Barriers to the implementation of targeted recruitment of students to medical school.

\begin{tabular}{lll}
\hline Barriers & Descriptions & Implementation strategies \\
\hline $\begin{array}{l}\text { Medical schools do not have a policy or } \\
\text { strategy for rural admissions }\end{array}$ & $\begin{array}{l}\text { - Absence of policy that dictates selection of } \\
\text { students from rural areas }\end{array}$ & $\begin{array}{l}\text { - Introducing affirmative selection policies that reserve } \\
\text { medical school places for rural students }\end{array}$ \\
\hline
\end{tabular}

Table 5. Barriers to the implementation of clinical rotation in rural areas during studies.

\begin{tabular}{lll}
\hline Barriers & Descriptions & Implementation strategies \\
\hline $\begin{array}{l}\text { Shortage of mentors in } \\
\text { rural areas }\end{array}$ & - Rural clinical rotation requires preceptors or mentors, which may not be & - The system must be in place \\
& available in many rural areas & - Regulations should be put in place to \\
& & enforce clinical rotation in rural areas \\
Inadequate support & - Isolation from consultants and experienced senior medical officer's forces & - Tele-education as a mentorship mechanism \\
and supervision & students to take on much more responsibility than they were usually comfortable & - Telephone support, onsite supervision \\
\hline
\end{tabular}

Table. 6 Barriers to the implementation of monetary and non-monetary incentives.

\begin{tabular}{|c|c|c|}
\hline Barriers & Descriptions & Implementation strategies \\
\hline $\begin{array}{l}\text { Risks of } \\
\text { nepotism }\end{array}$ & $\begin{array}{l}\text { - Incentives might find their way to those individuals } \\
\text { with the right connections and the difference in } \\
\text { incentives may foster behavior conducive to corruption. }\end{array}$ & - Strengthening transparency and information-sharing about incentives. \\
\hline $\begin{array}{l}\text { Absence of } \\
\text { policy for } \\
\text { incentives }\end{array}$ & $\begin{array}{l}\text { - There is no policy for incentives in the country. This } \\
\text { could lead to conflicts and might adversely affect other } \\
\text { programs }\end{array}$ & $\begin{array}{l}\text { - Develop a national policy for the use of incentives or ensure that } \\
\text { incentives that are used do not adversely affect other programs or create } \\
\text { undesirable inequities across different cadre of health workers }\end{array}$ \\
\hline Corruption & $\begin{array}{l}\text { - There is no system in place for managing incentives } \\
\text { and there is a risk of misuse of incentives and rewarding } \\
\text { people without merit }\end{array}$ & $\begin{array}{l}\text { - Transparent systems for managing and awarding incentives and ensuring } \\
\text { accountability }\end{array}$ \\
\hline $\begin{array}{l}\text { Weak health } \\
\text { human resource } \\
\text { information } \\
\text { systems }\end{array}$ & $\begin{array}{l}\text { - There is limited consistent information available on } \\
\text { retention and attrition trends to determine how effective } \\
\text { incentives are in improving rural health work force } \\
\text { retention. }\end{array}$ & $\begin{array}{l}\text { - Establishing well-functioning system for monitoring and evaluation or } \\
\text { indicators to track impact and outcomes } \\
\text { - Review incentive schemes regularly to ensure that they meet needs and } \\
\text { achieve their intended purpose } \\
\text { - Comprehensive plan for infrastructure development, including housing }\end{array}$ \\
\hline $\begin{array}{l}\text { Lack of } \\
\text { infrastructure }\end{array}$ & $\begin{array}{l}\text { - Providing some incentives is a challenge as lack of } \\
\text { infrastructures like standard houses and schools in } \\
\text { remote and rural areas is difficult }\end{array}$ & $\begin{array}{l}\text { for health staffs and schools for their children, which should bear fruit in } \\
\text { both the short and long term } \\
\text { - Increase investment in non-monetary incentives, such as housing and } \\
\text { instructional facilities, that are sustainable and build institutional capacity. }\end{array}$ \\
\hline
\end{tabular}

Table 7. Barriers to the implementation of continuous professional development (CPD).

\begin{tabular}{lll}
\hline Barriers & Descriptions & Implementation strategies \\
\hline $\begin{array}{l}\text { Under-staffed health } \\
\text { facilities }\end{array}$ & $\begin{array}{l}\text { - Facilities may have difficulty in releasing staff for CPD, especially when } \\
\text { courses are offered centrally. }\end{array}$ & $\begin{array}{l}\text { - Localization of training } \\
\text { - Support local training, which is accessible to } \\
\text { rural staff. Develop regional and district training, } \\
\text { as well as supporting on-the-job training. }\end{array}$ \\
& $\begin{array}{l}\text { - There is a conflict between service provision and finding time for learning. } \\
\text { - That is, health workers find it particularly difficult to take time out of / from } \\
\text { practice to undertake CPD as this can have a direct impact and consequences } \\
\text { for patient care and it can be difficult to find and/or fund locum GPs to fill in. }\end{array}$ & $\begin{array}{l}\text { - Courses need to be well-designed and flexibly } \\
\text { delivered. }\end{array}$ \\
$\begin{array}{l}\text { Lack of opportunity } \\
\text { to put new skills into } \\
\text { practice }\end{array}$ & $\begin{array}{l}\text { - Training attended needs to be matched with available jobs and equipment to } \\
\text { allow well-trained professionals to practice the techniques they have learned }\end{array}$ & - Developing capacities of rural facilities \\
\hline
\end{tabular}




\section{Conclusion}

In our review, we found that poor motivation and retention schemes, individual, organizational environment, local environment and work-related factors were the major causes for poor health workforce distribution in remote and rural parts of Ethiopia. Systematic reviews on impact of task shifting, clinical rotations in rural areas during studies and financial incentives have shown favorable results that may lead to increase the number of health workforce working in rural and underserved areas. However, the effect of nonfinancial incentives and continuous professional development on improving health workforce distribution is uncertain. None of the studies assessed the costs and cost effectiveness of all options. Therefore, given the limitations of the currently available evidence, there is a need for rigorous evaluative research on cost effectiveness of each option prior to widespread implementation.

\section{List of Abbreviations}

CPD- Continuing Professional Development, CSA- Central Statistical Agency, EDHS - Ethiopia Demographic and Health Survey, EPHI- Ethiopian Public Health Institute, FMoHFederal Ministry of Health, HRH- Human Resources for Health, LHW- Lay Health Workers, LMIC- Low and MiddleIncome Countries, RHB- Regional Health Bureau, SSA- SubSaharan Africa, WHO- World Health Organanization

\section{Ethical Approval}

Not applicable

\section{Availability of Data and Material}

All necessary data are within the manuscript

\section{Competing Interests}

All authors declare that they have no competing interests.

\section{Funding}

This research report is not funded by any funding organization.

\section{Authors' Contribution}

All co-authors contributed to the author. All authors critically reviewed the manuscript and approved the last version.

\section{Acknowledgements}

This policy brief was developed by Technology Transfer and Research Translation team at EPHI. The authors would like to acknowledge EPHI for Training and Technical arrangements. Our special thanks go to all participants of the policy dialogue for their invaluable comments and suggestions.

\section{References}

[1] WHO. Monitoring the building blocks of the health systems: A hand book of indicators and their measurement strategies. Geneva, Switzerland; 2010.

[2] Araújo E, Maeda A. How to Recruit and Retain Health Workers in Rural and Remote Areas In Developing Countries. A Guidance Note. 2013.

[3] WHO. World health report 2006: Working together for health. Geneva: WHO Press; 2006.

[4] Yohannes HJC, Girma B, Tushune K. Health Workforce Deployment, Attrition and Density in East Wollega Zone, Western Ethiopia. Ethiop J Heal Sci. 2010; 20 (1).

[5] WHO. WHO Estimates of Health Personnel: Physicians, Nurses, Mid-wives, Dentists, Pharmacists. Geneva, Switzerland; 2004.

[6] Padilha A, Kasonde J, Mukti G, Crisp N, Buch E. Human resources for universal health coverage: leadership needed. Bull World Heal Organ. 2013; 91.

[7] FMoH. Human Resource for Health Strategic Plan (20092025). Federal Democratic Republic of Ethiopia Ministry of Health. Addis Ababa, Ethiopia; 2014.

[8] FMoH. Health Sector Development Program IV 2010/11 2014/15. Addis Ababa, Ethiopia; 2010.

[9] Serneels P, Montalvo JG, Pettersson G, Lievens T, Butera JD, Kidanu A. Who wants to work in a rural health post? The role of intrinsic motivation, rural background and faith-based institutions in Ethiopia and Rwanda. Bull World Health Organ. 2010; 88:342-9.

[10] Feysia B, Herbst CH, Lemma W, Soucat A. The health workforce in Ethiopia: Addressing the remaining challenges. Washington DC: The World Bank; 2012.

[11] FMoH. Health and Health Related Indicators Version 2. Addis Ababa, Ethiopia; 2013.

[12] FMoH. Health Sector Development Programme IV Annual Performance Report EFY 2006 (2013/14). Addis Ababa, Ethiopia; 2013.

[13] Gebretekle GB, Fenta TG. Assessment of Pharmacists Workforce in Ethiopia. Ethiop J Heal Dev. 2013; 27 (0).

[14] Berhan Y. Medical doctors' profile in Ethiopia: Production, attrition and retention: In the memory of 100-years Ethiopian modern medicine \& the new Ethiopian Millennium. Ethiop Med J. 2008; 46 (Sup1).

[15] CSA. Summary and Statistics Report of the 2007 Population and Housing Census. Addis Ababa, Population Census Commission (Ethiopia). Addis Ababa, Ethiopia; 2008.

[16] FMoH. and Health related indicators (2007/8). Addis Ababa, Ethiopia; 2008.

[17] CSA. Ethiopia Demographic and Health Survey 2011 Central Statistical Agency. 2012. 
[18] Geresu T, Shiferaw M, Mitike G, Haile Mariam D. A brief review of the draft human resources for health strategic plan, Ethiopia; 2009-2020. Ethiop J Heal Dev. 2013; 27 (Special Issue 1).

[19] CSA. Ethiopia Demographic and Health Survey. Addis Ababa, Ethiopia; 2006.

[20] Gessessew A, Barnabas GA, Prata N, Weidert K. Task shifting and sharing in Tigray, Ethiopia, to achieve comprehensive emergency obstetric care. Int J Gynecol Obstet. 2011; 113:2831 .

[21] FMoFED. Ethiopia MDGs Report 2012. 2012.

[22] SURE. Guides for Preparing and Using Evidence-Based Policy Briefs 5. Identifying and addressing barriers to implementing policy options. 2011.

[23] SURE. Guides for Preparing and Using Evidence-Based Policy Briefs 2. Prioritising topics for policy briefs. 2011.

[24] Naicker S, Plange-Rhule J, Tutt RC, Eastwood JB. Shortage of Healthcare Workers in Developing Countries-Africa. Ethn Dis. 2009; 19.

[25] Getie GA, Betre ET, Hareri HA. Assessment of Factors Affecting Turnover Intention Among Nurses Working at Governmental Health Care Institutions in East Gojjam, Amhara Region, Ethiopia, 2013. Am J Nurs Sci. 2013; 4 (3):107-12.

[26] Ture J A. Assessment of the Magnitude, Patterns and Determinant Factors of Health Worker Migration from the Public Health Sectors: A descriptive case study in East Hararghe zone of Oromiya, Eastern Ethiopia. Addis Ababa University; 2008.

[27] Abraham Y, Azaje A. The new innovative medical education system in Ethiopia: Background and development. Ethiop J Heal Dev. 2013; 27 (Special Issue 1).

[28] FMoH. The Federal Democratic Republic of Ethiopia Ministry of Health Health Sector Transformation Plan ( HSTP). Addis Ababa, Ethiopia; 2015.

[29] WHO. Task Shifting Global Recommendations and Guidelines. Geneva, Switzerland: WHO Document Production Services; 2008.

[30] Lehmann U, Dieleman M, Martineau T. Staffing remote rural areas in middle-and low-income countries: A literature review of attraction and retention. BMC Health Serv Res. 2008; 8 (19).

[31] WHO. Task shifting to tackle health worker shortages. Strengthening health services to fight HIV/AIDS. 2007.

[32] Munga M a, Kilima SP, Mutalemwa PP, Kisoka WJ, Malecela MN. Experiences, opportunities and challenges of implementing task shifting in underserved remote settings: the case of Kongwa district, central Tanzania. BMC Int Health Hum Rights. 2012; 12:27.

[33] Laurant M, Reeves D, Hermens R, Braspenning J, Grol R,
Sibbald B. Substitution of doctors by nurses in primary care (Review) Substitution of doctors by nurses in primary care. 2004.

[34] Horrocks S, Anderson E, Salisbury C. Systematic review of whether nurse practitioners working in primary care can provide equivalent care to doctors. BMJ. 2002; 324.

[35] Lewin S, Munabi-Babigumira S, Glenton C, Bosch-Capblanch $\mathrm{DK}$, Van X, Be W, et al. Lay health workers in primary and community health care for maternal and child health and the management of infectious diseases (Review). 2010.

[36] WHO. Increasing access to health workers in remote and rural areas through improved retention: global policy recommendations. Geneva, Switzerland; 2010.

[37] Grobler L, Bj M, Mabunda S. Interventions for increasing the proportion of health professionals practising in rural and other underserved areas ( Review ) SUMMARY of Findings for the Main Comparison. 2015; (6).

[38] Grobler L, Marais BJ, Mabunda S, Marindi P, Reuter H, Volmink J. Interventions for increasing the proportion of health professionals practising in rural and other underserved areas (Review). Cochrane Database Syst Rev Art. 2009; (2).

[39] Okwundu CI. Which interventions increase the recruitment and retention of health workers practising in under-served and rural areas? A SUPPORT Summary of a systematic review. 2011; 9 .

[40] WHO. The world health report 2000 - health systems: improving performance. Geneva, Switzerland; 2000.

[41] Nurses IC of, Federation IP, Federation WD, Association WM, Federation IH, Therapy WC for P. Guidelines: Incentives for Health. 2008.

[42] Bärnighausen T, Bloom DE. Financial incentives for return of service in underserved areas: a systematic review. BMC Health Serv Res. 2009; 9 (86).

[43] Frehywot S, Mullan F, Ross PWP\& H. Compulsory service programmes for recruiting health workers in remote and rural areas: do they work? Bull World Heal Organ. 2010; 88:364 70 .

[44] Peña S, Ramirez J, Becerra C, Carabantes J, Arteaga O. The Chilean Rural Practitioner Programme: a multidimensional strategy to attract and retain doctors in rural areas. Bull World Heal Organ. 2010; 88.

[45] Gray LG and I. Continuing Professional Development - a Brief Guide. The Psychologist Vol 19 No 9. 2006; 19 (9).

[46] EU. Recruitment and Retention of the Health Workforce in Europe. 2015.

[47] Kotzee TJ CI. What interventions do South African qualified doctors think will retain them in rural hospitals of Limpopoprovince of South Africa? Rural Remot Heal. 2006; 6 (3). 